\title{
O uso da argumentação na acepção de Stephen Toulmin articulado à abordagem histórico-epistemológica com enfoque no aluno: um caminho possível para construção da aprendizagem em relatividade
}

\author{
Maria Derlandia de Araújo Januário*, Neusa Teresinha Massoni**
}

\section{Resumo}

Apresentamos uma proposta de investigação e intervenções no campo temático da História, Filosofia e Sociologia da Ciência articulada a um tema de Física Moderna e Contemporânea (FMC) tendo como público alvo estudantes da Escola Básica e seus professores em atividade, que será desenvolvida no curso de doutorado de um Programa de Pós-Graduação em Ensino de Física. São dois os objetivos principais da proposta: contribuir para uma educação científica que valorize e integre aspectos da História e Filosofia da Ciência (HFC) no processo de ensino-aprendizagem de conceitos e princípios de Relatividade, buscando problematizar visões ingênuas sobre a natureza da ciência; e construir uma sinergia entre Universidade e escola, focalizando a escuta e a compreensão da identidade do estudante enquanto sujeito da escolarização, a discussão, a divulgação e os usos da argumentação científica, na acepção de Stephen Toulmin (1922-2009).

Palavras-chave: História e Filosofia da Ciência; Física Moderna e Contemporânea; Relatividade; Argumentação Científica.

* Doutoranda em Ensino de Física, Programa de Pós-Graduação em Ensino de Física, Instituto de Física, UFRGS. E-mail: mderlandiaajanuario@gmail.com. ORCID: https://orcid.org/0000-0001-9781-8519

* Programa de Pós-Graduação em Ensino de Física, Instituto de Física, UFRGS. E-mail: neusa.massoni@ufrgs. br. ORCID: https://orcid.org/0000-0002-1145-111X 


\section{Introdução}

A literatura da área de Ensino de Física tem dado importância à História e Filosofia da Ciência (HFC), tanto na estruturação dessa área do conhecimento (MATTHEWS, 1995) quanto no que se refere às contribuições à didática das ciências (MARTINS, 2007) e como facilitadora da intepretação de fundo de conceitos de Física Moderna e Contemporânea (FMC) (SOLBES; SINARCAS, 2009; CUESTA; MOSQUERA, 2017). Há certo consenso na área de que a articulação da HFC na educação científica pode despertar nos estudantes uma visão crítica em relação à ciência e à construção do conhecimento científico, através da (re)elaboração ou transformação de conceitos e da análise das relações entre sociedade e ciência, conduzindo-os a reconhecer que a ciência não é algo pronto e acabado, mas é fruto da atividade humana, colaborativa, processual, inconclusa e não neutra (OLIVEIRA; MARTINS; DA SILVA, 2020; DAMASIO; PEDUZZI, 2017; RAICIK; PEDUZZI, 2016; MONTEIRO; MARTINS, 2015; FORATO, 2011; MASSONI; MOREIRA, 2014; PIETROCOLA; MARTINS, 2011; MASSONI, 2010; ERTHAL; LINHARES, 2009; MOREIRA; MASSONI; OSTERMANN, 2007).

Por outro lado, a inserção da FMC na Educação Básica tem sido abordada há décadas no Ensino de Física, ressaltando sua importância para compreensão dos fenômenos ligados a situações vividas pelos estudantes, sejam de origem natural ou tecnológica (CAVALCANTE; TAVOLARO, 2001; SILVA; ARENGHI, 2013; ROCHA; RICARDO, 2016). Defendemos que mostrar aos estudantes, de forma explícita, a ciência como uma construção humana e evolutiva pode possibilitar-lhes uma leitura do mundo atual e potencializar a evolução conceitual-epistemológica de suas concepções (GARCIA; LOCH, 2009; EL-HANI; TAVARES; ROCHA, 2004; RAICIK, 2020).

Vale salientar que as políticas públicas para o Ensino Médio recomendam o uso da História e Filosofia da Ciência desde longa data: em 1999, nos Parâmetros Curriculares Nacionais para o Ensino Médio (PCNs) (BRASIL, 1999), em 2002, nas Orientações Educacionais Complementares aos Parâmetros Curriculares Nacionais para o Ensino Médio (PCN+) (BRASIL, 2002) e em 2012, nas Diretrizes Curriculares Nacionais para o Ensino Médio (BRASIL, 2012). Esses documentos, em linhas gerais, têm sugerido que é relevante abordar HFC como uma das possíveis vias para se alcançar uma educação científica alinhada à formação cidadã. Mais recentemente, a Base Nacional Comum Curricular (BNCC) diz que "[...] a contextualização social, 
histórica e cultural da ciência e da tecnologia é fundamental para que elas sejam compreendidas como empreendimentos humanos e sociais" (BRASIL, 2018, p. 49). Nesse sentido, a enculturação científica não deve ser percebida pelos estudantes apenas com referência aos conhecimentos que fundamentam as modernas tecnologias, mas como uma construção abrangente que tem reflexos no seu cotidiano, na juventude, na sociedade e na compreensão dos fundamentos epistemológicos que garanta uma educação científica consistente (BRASIL, 2012).

Entretanto, apesar das recomendações para a utilização de elementos da HFC serem persistentes e apontarem distintas vantagens, faltam, sobretudo, condições reais para que essas propostas possam ser implementadas em sala de aula (ERTHAL; LINHARES, 2009). Massoni (2010) aponta a necessidade de uma formação de professores que melhor os instrumentalize, para que assim se sintam mais confortáveis para promover essa discussão ; por outro lado, pouco se discute e se investiga sobre como os sujeitos a quem se destina a educação - os estudantes - percebem a escola e a educação que ali recebem (SACRISTÁN, 2005). Assim, é imprescindível, em nossa visão, o desenvolvimento de pesquisas que contemplem a complexidade do processo educativo, capazes de envolver aspectos que muitas vezes são deixados em segundo plano, para além da necessária formação inicial e continuada dos professores atuantes, como a interação sinérgica universidade-escola-estudantes, buscando compreender suas necessidades, especialmente captando a percepção e o sentir dos alunos, cuja presença entre os educadores, pais, professores, legisladores costuma ser naturalizada.

Portanto, nossa pesquisa tem um olhar direcionado à escuta ao aluno, enfoca a escuta e o diálogo para a compreensão de seu lugar na história, na cultura, nas/ das formas por ele utilizadas para construir argumentos científicos, na acepção de Stephen Toulmin (2006), vislumbrando a possibilidade de melhorar a aprendizagem da Física e a percepção de seus usos sociais, enquanto um referente essencial na construção do conhecimento. Desta forma, a teoria da argumentação de Toulmin (2006) e concepção de aluno de Sacristán (2005) são tomadas como referenciais teóricos que contribuem para uma sinergia entre universidade, pesquisadora, escola, alunos e professores atuantes.

Assim, buscaremos: i) contribuir com a promoção de um processo de ensino-aprendizagem com enfoque conceitual, incluindo formalismos na medida do possível, tomando a fundamentação histórica-epistemológica da Relatividade Restrita 
como pano de fundo; ii) construir um ambiente de sinergia entre universidade/ pesquisadora e escola, valorizando a escuta, a compreensão das identidades dos alunos, diversificando e tornando o processo de ensino-aprendizagem de Física mais atraente, mais crítico (investindo no uso de processos argumentativos) e engajador, baseados na crença de que estes saberes podem conviver com as concepções e construtos pessoais e, ao mesmo tempo, adquirir significância para as suas vidas.

De acordo com Mortimer (2013), esse modo de analisar o mundo se fundamenta na ideia de que cada indivíduo tem formas diferentes de pensar, interpretar e assimilar um mesmo conceito, isto é, para cada conceito científico é possível construir um perfil, a partir de compromissos epistemológicos e ontológicos, que desencadeia diversas compreensões perante um mesmo conceito. Destarte, aprender ciências seria aproximar as maneiras de pensamento das pessoas à forma argumentativa pela qual a ciência é construída e debatida entre seus membros, nas comunidades científicas (NASCIMENTO, 2008), sem a pretensão de tomar o aluno como um pequeno cientista, mas, ao contrário, escutando suas percepções, intencionalidades e opiniões. Guimarães e Massoni (2020) acrescentam ainda que incitar a argumentação em ciências, nesta perspectiva, é importante para uma melhor compreensão do trabalho científico, destacando que tanto o estudante quanto o educador podem ter uma postura ativa frente ao processo de aprendizado de temas de Física, especialmente quando se leva em conta as escolhas de temáticas e os interesses dos estudantes.

Assim, a presente proposta de investigação e intervenções no campo temático da História, Filosofia e Sociologia da Ciência coloca o aluno e seus professores em atividade no centro do processo investigativo no âmbito da Educação Básica, a ser desenvolvida em um curso de doutorado de um Programa de Pós-Graduação em Ensino de Física. O intuito, como já mencionado, é de contribuir para uma educação científica que valorize e integre aspectos da História e Filosofia da Ciência (HFC) no processo de ensino-aprendizagem de Relatividade e a construção de uma efetiva sinergia entre Universidade e escola capaz de focalizar a escuta, a discussão, a divulgação e os usos pelos alunos da argumentação, na acepção de Stephen Toulmin (1922-2009).

A escolha do conteúdo de Relatividade Restrita (ou Teoria da Relatividade Especial), parece-nos uma opção apropriada, uma vez que historicamente é considerada um dos pilares da FMC e também por ter, a pesquisadora, trabalhado essa temática durante a realização do Mestrado Profissional em Ensino de Física em 
2020 (JANUÁRIO, 2020), oportunidade em que foi possível perceber que essa seria, para muitos alunos, a única oportunidade de estudar aspectos conceituais básicos, como também epistemológicos, dessa encantadora teoria, que que pode também ser percebida como um momento criativo na ciência (GURGEL; PIETROCOLA, 2011). Alguns artigos recentes reforçam essa importância dessa temática na educação científica como Chiriacescu,et all (2020); Kersting; et all (2018) e Arriassecq; Greca e Cayul (2017).

\section{ensino de relatividade e a história e filosofia em sala de aula}

A busca pela inserção de elementos da História, Filosofia e Sociologia da Ciência, como mencionado na Introdução deste texto, vem sendo há décadas discutida e indicada como um possível caminho para promover uma visão crítica sobre a natureza da ciência e seu papel na sociedade, descontruindo a noção ingênua e ainda bastante presente no ensino-aprendizagem de Física, de que a ciência está assentada em conceitos e teorias prontas e acabadas (AQUINO, 2020; BELTRAN; RODRIGUES; ORTIZ, 2011; PEREIRA; MARTINS, 2011; MASSONI; MOREIRA, 2014). Fatores como conteúdos insuficientes ou simplistas relacionados ao assunto de HFC presentes nos livros didáticos (que na maioria das vezes trazem um apanhado voltado para o formalismo matemático e preparação de ENEM e vestibulares em geral); cultura conteudista do ensino de Física; priorizando o desenvolvimento de habilidades, atitudes e crenças epistemológicas e didáticas inadequadas de professores (MASSONI, 2010) e uma estrutura institucional de ensino de ciências pouco voltada à transformação de concepções sobre a natureza da ciência dificultam à implementação da HFC nas aulas de Física. Assim, as dificuldades vão desde a visão do que é ciência e por quem ela é feita, até questões estruturais, como espaço nos currículos (HÖTTECKE; SILVA, 2011; AQUINO, 2020).

Para Sasseron e Machado (2017), os currículos de Ciências, e de Física, voltados a uma alfabetização científica, conceito este bastante polissêmico e por isso neste texto preferimos utilizar a expressão enculturamento científico, tem grande preocupação em engajar de forma ativa os alunos em tarefas, pesquisas e investigações sobre temas científicos, propiciando um entendimento contextualizado dos conceitos físicos associados e também construindo experiências e conceitos sobre como se faz ciência, quais 
são seus objetos de estudo e que papel a ciência tem na sociedade. $O$ enfrentamento de questões sociocientíficas relevantes para a sociedade moderna exige não apenas um enculturamento científico, no sentido de captar e compreender conceitos e teorias, mas também dominar aspectos históricos e epistemológicos associados a controvérsias científicas e à superação das controvérsias no tempo (JUNGES; MASSONI, 2018), podendo ajudar professores e alunos em discussões atuais e na tomada de decisões mais conscientes, marcando uma atuação ativa na sociedade, pois como o filósofo italiano Antonio Negri (2015, p. 25-26) pondera, "a singularidade está dentro do comum inserida em uma substância eterna que vive e se transforma por um movimento ético ou relação de composição inter-humana". Para Negri, o poder absoluto não está no capital, ou no Estado, só podendo existir no coletivo (que ele chama "ser-multidão"); a potência do "ser-multidão" se compõe na diferença das singularidades, no ser humano que se questiona sobre a expressão dos limites da relação com os dispositivos de gestão coletiva do comum; e tal potência é tanto maior quanto mais se estende e intensifica a associação; dessa forma não há lugar para o individualismo; a potência constitutiva está nos deslocamentos e nas transformações coletivas. Por isso a importância de formar cidadãos críticos, seres capazes da vida civil.

Arthury e Terrazan (2018) recomendam que um tratamento didático da natureza da ciência, junto a alunos de Física do Ensino Médio demanda considerar aspectos relacionados ao uso de textos nas aulas, à apresentação de termos específicos da epistemologia aos alunos, e às dificuldades enfrentadas tanto pelos alunos quanto pelos professores. Por essas razões que a revisão sistemática da literatura e das políticas públicas no Brasil tendem a apontar, consideramos que a integração da HFC através da Relatividade Restrita à sala de aula da Educação Básica é fundamental para a formação de cidadãos mais reflexivos e preparados para os grandes desafios do século XXI.

Rodrigues, Sauerwein e Sauerwein (2014) discutem as potencialidades da inserção da FMC no Ensino Médio, dando especial ênfase ao ensino da Teoria da Relatividade Restrita por meio do estudo e explicação do Sistema de Posicionamento Global (GPS), considerando a dilatação do tempo. Descrevem um planejamento didático que aproxima os alunos das situações do cotidiano e que estão relacionados com exemplares tecnológicos, fazendo com que os alunos assumissem o papel principal na construção do conhecimento e percebessem a ciência como uma construção humana, com importantes aplicabilidades no seu cotidiano. 
Reis e Reis (2016) discutem a importância de abordar histórica e filosoficamente os conceitos de espaço e tempo na Educação Básica e apresentam os relatos de uma experiência realizada em uma sala de $1^{\circ}$ ano do Ensino Médio, trabalhando as temáticas: 1) Galileu e a geometrização do espaço e tempo; 2) A Mecânica de Newton e o espaço e tempo absoluto; 3) A Relatividade de Einstein e o espaço e tempo relativo. À luz desse panorama histórico e filosófico, construíram uma sequência didática que foi implantada e avaliada através de uma pesquisa-ação de uma forma gradual, promovendo a reflexão dos alunos sobre a transitoriedade dos conceitos científicos.

Matos e Massoni (2019) narram a aplicação de uma estratégia didática para introduzir conceitos de Física a alunos de anos finais do Ensino Fundamental, buscando gerar uma experiência positiva nos alunos e possibilitando que esses construam uma visão de ciência alinhada a visões epistemológicas contemporâneas, abordando três diferentes paradigmas: o paradigma de Aristóteles, do lugar natural; o de Newton, da Gravitação Universal; e o de Einstein, da Teoria da Relatividade Geral. Utilizaram aspectos da História e Filosofia da Ciência e tentaram mostrar aos alunos que a Ciência é uma construção humana, provisória, histórica, e que ela está associada a contextos sociais, econômicos e históricos, lhes possibilitando refletir sobre a atividade científica e para que o aprendizado da Física faça sentido ao jovem, em sala de aula.

No trabalho de Oliveira e Gomes (2016), os autores apresentam a história, os anseios, as curiosidades, as verdades reviradas vividas pelos físicos no início do Século XX e a inserção da Relatividade Restrita através de um teatro científico tendo como personagens protagonistas "Ensino Tradicional" e "Física Nova". O intuito foi que, a partir desse diálogo, os alunos do Ensino Médio percebessem como a ciência evolui e possibilitasse um ensino de Física atrativo e divertido.

Guerra, Braga e Reis (2007) trazem em seu trabalho um debate em torno do ensino de Física, trabalhando com uma proposta curricular de inserção do estudo das Teorias da Relatividade Restrita e Geral no primeiro ano do Ensino Médio. A proposta foi construída com uma abordagem histórica-filosófica, fazendo uma relação entre a Física com outras produções culturais, privilegiando trabalhar com os alunos as questões científicas respondidas pelos trabalhos de Albert Einstein.

De maneira similar, Karam, Cruz e Coimbra (2016) apresentam parte de uma sequência didática, cujo objetivo foi abordar tópicos da Teoria da Relatividade Restrita com alunos também do primeiro ano do Ensino Médio. Os autores trabalharam 
os aspectos históricos a partir do caráter conceitual da física de Galileu e de como ela serviu de porta de entrada para o tratamento de tópicos relativísticos, discutindo assim, como essa temática pode ser abordada em sala de aula em um viés histórico.

Com ênfase na formação de professores, Giacomelli, Perez e Rosa (2019) relatam o desenvolvimento, a aplicação e a avaliação de uma proposta didática para contemplar tópicos da Teoria da Relatividade Restrita e da Teoria da Relatividade Geral no Ensino Médio. O estudo foi desenvolvido junto a um grupo de alunos universitários - futuros professores de Física. O objetivo foi investigar as contribuições dessa proposta didática como favorecedora da aprendizagem para estimular os acadêmicos a adotar em sala de aula futuramente, como docentes, temas relevantes da FMC, mostrando o aspecto da evolução da ciência e suas potencialidades.

Neste sentido, o que trazemos aqui é uma revisão bastante preliminar da literatura colocando-a muito mais como uma etapa importante e precedente às implementações e estudos empíricos que pretendemos desenvolver ao longo da implementação deste projeto de investigação. Conforme Rodrigues (2001, p. 23):

A inserção da $\operatorname{TRR}^{1}$ se funda basicamente em três aspectos: a mudança de padrão de raciocínio e interpretação da realidade aliada à abstração e sofisticação do pensamento, graças à concepção de tempo como uma quarta dimensão; a possibilidade dessa teoria servir de porta de entrada para outros tópicos da FMC e, finalmente, pela necessidade de abordagem de um tema tão presente na sociedade através da divulgação científica.

Acreditamos, portanto, que os argumentos dos alunos poderão ser aprimorados e colocados em prática a partir do "modelo de Toulmin" que é um modelo importante na análise sequencial de argumentos, uma vez que estabelece relações entre vários elementos presentes nas argumentações. Desta forma, consideramos também que uma aproximação universidade-escola e a escuta atenta a alunos e professores atuantes, que lidam diretamente com eles, poderá ser útil e necessária para alcançarmos êxito no auxílio e tentativa de superação de alguns desses desafios, tornando possível a implementação explícita da HFC em sala de aula, com efetivo uso da argumentação científica na acepção de Toulmin.

Utilizaremos como aporte teórico os estudos do J. Gimeno Sacristán (1947) que é autor de diversas publicações sobre cultura, ensino e educação, sobre a escola e seus problemas educativos. Dentre suas obras, o livro intitulado "Aluno como Invenção" (2005) coloca o aluno como uma construção social e resgata o valor do sujeito 
escolarizado como um referente essencial para projetar, desenvolver e avaliar a qualidade da educação, o que justifica nossa escolha pelo autor, por trazer o aluno como sujeito fundamental no desenvolvimento educacional, oportunizando para que exponha seus pensamentos, argumentos, sendo ativos e não apenas receptores da educação. Acreditamos, portanto, que os processos argumentativos dos alunos poderão ser colocados em prática a partir do "modelo de Toulmin", que é também um referencial importante para a análise sequencial de argumentos, uma vez que estabelece relações entre vários elementos e as argumentações. Dessa forma, aplicaremos as concepções de Stephen Toulmin como referencial teórico-epistemológico, juntamente com as ideias de Sacristán, além de tomar Toulmin como referencial metodológico que serão esplanadas a seguir.

\section{Referencial teórico-epistemológico e metodológico de Stephen Toulmin}

Stephen Toulmin (1922-2009) graduou-se em Matemática e Física no King's College e doutorou-se em Filosofia da Ciência na Universidade de Cambridge e é considerado um dos epistemólogos da ciência mais influentes do século XX. A ciência é, para Toulmin, uma empresa racional composta por disciplinas que são entendidas como entidades históricas em evolução. Assim, as novidades intelectuais constantemente surgem e são propostas no interior da comunidade científica, mas apenas algumas são transmitidas às gerações seguintes pelo processo de inovação $\mathrm{e}$ seleção, ou seja, a própria comunidade científica funciona como crítica seletiva e em muitos casos, ao mesmo tempo, como filtro das inovações propostas pelos cientistas (ou grupos de cientistas).

A epistemologia toulminiana investiga tanto os processos da compreensão humana, como a forma como progride o conhecimento científico, pondo-os em termos de um processo evolucionário. Nessa dinâmica ganha relevância a argumentação científica. Toulmin se debruçou nesse ponto e propôs o que ficou conhecido como o “modelo da argumentação de Toulmin" (2003), que corresponde a um modelo textual de conceber o funcionamento da argumentação. Trata-se de uma proposta em que a passagem do argumento à conclusão não ocorre de maneira contínua, mas é fundamentada em um conjunto de princípios que conduzem a uma conclusão com justificativas, sendo esse um dos pontos passíveis de análises em sala de aula. Propor 
situações e escutar como os alunos conseguem absorver e (re)elaborar argumentos ao defender uma ideia, um conceito, uma teoria, além de explorar a não linearidade e cumulatividade da ciência, já que, algumas ideias serão descartadas no caminho e outras serão mais elaboradas com relação ao assunto estudado em sala de aula.

Portanto, para Toulmin (2006), pode-se produzir argumentos para diversas finalidades, o que não significa que sua defesa pode ser dada por uma asserção formal direta; o apoio que a conclusão recebe advém das asserções e das proposições que compõem as suas premissas. A validação advém, sobretudo, da habilidade de criticidade desses argumentos, que pode se dar por proposições ou dados, qualificadores, garantias, condições de aceite ou refutação e conclusões; e por uma relação complexa entre estes elementos. Os warrants $(\mathrm{W})$ - garantias - são chamadas por Toulmin de qualificadores modais; conferem certo grau de força justificatória às conclusões a partir das premissas dadas, ou de refutadores, se estes têm o papel de anular a justificação e, com isso, não conferir a garantia de que a conclusão se siga logicamente das premissas (GUIMARÃES; MASSONI, 2020). Apesar da explicitação da garantia em que se gera ser condição do próprio raciocínio argumentativo, a substância dos dados e das garantias é muito variável e depende das escolhas de quem avança os dados. Um raciocínio argumentativo não é um cálculo, mas um modo de pensar, a questão da validade articula-se para a questão da aceitabilidade dos dados avançados, da relevância que eles apresentam para a tese (dados) e da suficiência que revelam para que essa possa ser considerada como fundamentada.

Nesse sentido, acreditamos que as ideias de Toulmin podem ser tomadas como um referencial epistemológico para promover a discussão e aprofundamento da visão de ciência em sala de aula sobre Relatividade Restrita e também como referencial metodológico enquanto tentativa de compreender como os alunos captam os conceitos, (re)interpretam e como se dá a mudança conceitual. Na escola, esse "modelo" seria parte de um conjunto de atividades desenvolvidas junto com alunos, com orientação do professor e da pesquisadora, onde os atos de avaliação, justificação e revisão propiciam um aprendizado em que determinadas metas e objetivos devem ser alcançados, em detrimento de processos e rotinas de memorização que conduzam a uma espécie de aprendizagem mecânica.

Em nossa proposta, utilizaremos uma abordagem histórico-epistemológica e conceitual de postulados e princípios da Relatividade Restrita (Simultaneidade, dilatação temporal, contração do comprimento e energia relativística, como conse- 
quência dos dois postulados), com intuito de promover em sala de aula a prática da argumentação dos alunos, na acepção de Toulmin, analisando quais tipos de argumentos se desenvolvem e os modos como se dão na construção do conhecimento. De acordo com Mortimer, Sepúlveda e El-Hani (2013), esse modo de analisar o mundo se fundamenta na ideia de que cada indivíduo tem formas diferentes de pensar, interpretar e assimilar um mesmo conceito, isto é, para cada conceito científico é possível construir um perfil a partir de compromissos epistemológicos e ontológicos, que desencadeia diversas compreensões perante um mesmo conceito.

Assumimos que aprender a pensar é, de certa forma, aprender a argumentar. Mais ainda, aprender a ciência física seria aproximar as maneiras de pensamento das pessoas à forma argumentativa pela qual a ciência é construída e debatida entre os membros das comunidades (NASCIMENTO, 2008). Guimarães e Massoni (2020), acrescentam ainda que a argumentação em ciências, nesta perspectiva, é importante para a compreensão do trabalho científico, destacando que tanto o aluno quanto o educador devem ter uma postura ativa frente ao processo de aprendizado de temas de Física.

\section{Referencial humanista de Sacristán: o aluno em foco}

Sacristán (2005, p. 11) afirma que "tudo o que nos é familiar tendemos a naturalizar, como se sua existência sempre tivesse existido e, inevitavelmente, tivesse de existir". Ele alerta que nossa experiência cotidiana é enriquecida com discursos e representações tomados de outros, que projetam seus pontos de vista. É por esse processo que construímos os sujeitos que participam dos distintos cenários de nossas vidas. A educação é um desses cenários. $O$ aluno é, assim, uma construção social inventada pelos adultos. Naturalizamos, como "menores", sua existência entre nós ao vê-los no nosso cotidiano; sua voz não nos importa e, dessa forma, não os consultamos sobre o que significa ter essa condição social - de seres escolarizados, em geral, entre 4 e 17 anos. Adverte o autor que essa é uma tendência na maioria dos países do mundo, não nos perguntamos se deste estado (de "ser escolarizado") sempre surgem consequências positivas, se poderia ser diferente, como vivem essa tarefa, com que dificuldades ou preocupações vão às aulas, que desejos deixam nas portas das escolas (SACRISTÀN, 2005, p. 14). 
Para ele, a pesquisa educacional tem tomado como sujeito de pesquisa nas últimas décadas o professor, a formação do professor, dando atualidade a um discurso que também dividiu e parcelou o objeto de estudo. $O$ sujeito professor está muito mais presente nas pesquisas da área do que o sujeito aluno. Em um breve apanhado na plataforma Periódicos da CAPES, embasados nas buscas similares feitas por ele na Espanha, obtivemos nas últimas duas décadas, buscando pelas palavras-chave "aluno" e "professor", os seguintes números de trabalhos revisados por pares 7.073 e 1.198.147, respectivamente; e para a busca "estudantes" e "professores" os resultados foram os seguintes: 16.991 e 19.902. Este desequilíbrio mostra que, de fato, o sujeito professor está mais presente nas pesquisas no Brasil, o que segue padrões internacionais como mostra Sacristán (2005).

Além de centrar no professor, o discurso educacional tem se centrado na instituição escolar, em sua eficácia, no currículo, no êxito ou no fracasso e na acomodação da educação ao sistema produtivo, tendo deixado de fora preocupações sobre o que pensam os alunos sobre a educação, sobre gênero e cultura étnica como geradores de desigualdades entre os alunos. Nesse sentido, buscaremos fazer esse regaste da voz, pensamentos e ideias dos alunos nas aulas de Física com uso da argumentação na acepção de Toulmin, mas também através de grupos focais e outras estratégias que permitam fazer surgir o discurso, a voz dos alunos.

\section{Alguns aspectos metodológicos e implicações para o ensino de Física}

O uso da argumentação na acepção de Toulmin para o ensino de Ciências e o papel incentivador do professor diante dessa prática argumentativa são fundamentais para que possamos escutar o estudante, suas reflexões e críticas, pois este “(...) não é uma tábua rasa a ser preenchida pelos adultos, mas ele é o agente ativo em seu desenvolvimento" (SACRISTÁN, 2015, p. 22). Dessa forma, pensamos em desenvolver investigações e intervenções articulando um tópico de FMC com o campo temático da História e Filosofia da Ciência, tendo como público alvo os alunos e seus professores, em sala de aula da Educação Básica, preferencialmente em alguma escola da região metropolitana de Porto Alegre; a proposta é promover pesquisas empíricas com alunos do Ensino Médio, em uma sinergia entre escola, universidade e pesquisadora. 
Trata-se de uma proposta de investigação de natureza qualitativa em Educação em Ciências porque valoriza as percepções humanas, os aspectos subjetivos dos participantes, as opiniões das pessoas sobre fenômenos sociais (STAKE, 2011). A investigação qualitativa procura entender fenômenos do dia a dia escolar em toda sua complexidade, incertezas e em seu contexto natural (BOGDAN; BIKLEN, 1994).

A abordagem qualitativa tem como características: (i) o investigador como principal instrumento de pesquisa, uma vez que está imerso no ambiente natural do contexto escolar; (ii) exige um detalhamento descritivo e abundante dos dados obtidos (valorização de cadernos de campo e observações cuidadosas); (iii) possui interesse de entender a forma como as pessoas (alunos) dão significados as suas ações e, em nosso caso, à escolarização e à educação científica; (iv) ela é interpretativa, não pode prescindir de percepções do próprio pesquisador, que não é um sujeito neutro; (v) é experiencial, valorizando o processo de observação; (vi) é naturalística, no sentido de o pesquisador buscar ser fiel aos dados e não interferir neles, embora o pesquisador não possa ser tomado como instrumento neutro, como já citado; (vii) ela é situacional e personalística, pois valoriza a regionalização e o contexto cultural local sem pretensões de construir generalizações, mas enfatizando as singularidades, ainda que as explicações dos fenômenos educacionais busquem por certos padrões (BOGDAN; BIKLEN, 1994).

Para o registro dos acontecimentos e das atividades de ensino-aprendizagem buscar-se-á utilizar uma diversidade de fontes de dados no intuito de termos uma visão mais geral do fenômeno estudado, por exemplo: observação participante ativa (da pesquisadora), entrevista, uso do caderno de campo, intervenção com atividades e apresentação de conceitos de Relatividade em módulos de ensino com uso da argumentação, júri simulados com questões expositivas e debates. Todas essas ideias buscam fazer uso da argumentação de Toulmin e explanar em sala de aula tópicos da Física Moderna, no caso, Relatividade. Kersting et al. (2018), salientam que conceitos de espaço e tempo são importantes, porém, não há aprofundamento, nas aulas de ciências, sobre a sua epistemologia e história na perspectiva de uma relatividade especial e uma abordagem crítica ao ensino destas concepções, o que seria fundamental na educação, pois se traria um olhar crítico e investigativo para a sala de aula. Pitts et al. (2013) acrescentam ainda que os conceitos relacionados com a física einsteiniana podem ser apresentados logo na Educação Básica e não apenas nos cursos superiores como geralmente acontece, uma vez que, adequando a 
linguagem à idade, pode resultar em uma aprendizagem mensurável. Os resultados dos autores indicaram uma melhoria estatisticamente significativa na compreensão conceptual das crianças do sexto ano (entre 10 e 11 anos) sobre o espaço curvo e um interesse das crianças pelo o assunto.

É possível que haja algumas adaptações para o formato online nas intervenções, já que a situação pandêmica que estamos vivenciando desde o primeiro semestre de 2020 ainda continua. Desta forma, os módulos de ensino podem ser acompanhados com recursos digitais para que envolvam o estudante nesse mundo virtual e, ao mesmo tempo, esses sejam engajados e interajam de forma a expor seus argumentos, percepções, necessidades, expectativas e ideias. Nesse sentido, Chiriacescu et al. (2020) apresentam uma ferramenta didática digital que consiste em apresentar as ações por meio de uma animação projetada em uma superfície de quadro branco. Os conceitos, símbolos, palavras-chave são desenhados sob o olhar do observador, ajudando-o a compreender o fluxo natural dos acontecimentos que, para os autores, é eficaz na compreensão do fenômeno e na motivação dos estudantes para o estudo do conteúdo. Morarua, Stoica e Miron (2010) apresentaram tópicos de FMC por meios de software educativo fazendo uma interdisciplinaridade entre Matemática, Química e Biologia, cujo objetivo era buscar um ensino ativo e interativo levando os estudantes a descobrir o prazer da investigação e da aprendizagem de argumentos para uma mudança de paradigma no processo de ensino de ciências. Dessa forma, é necessário investigar mais propostas que já se mostraram bem-sucedidas, conduzindo as devidas adaptações sobre como implementar um tópico da FMC, tendo como pano de fundo a HFC, através da argumentação de Toulmin no contexto de sala de aula, o que poderia se refletir na produção e consolidação de um conhecimento metodológico e analítico específico para o campo.

As análises dos tipos, validade, qualidade das argumentações e discussões que ocorrerão em sala de aula, bem como a escuta das falas dos alunos sobre suas percepções dos processos de escolarização e educação científica, serão feitas seguindo o modelo argumentativo de Toulmin, complementado na medida da detecção da necessidade por grupos focais e entrevistas. A investigação será estruturada em dois momentos: o primeiro se refere ao estudo e revisão de literatura de como tomar a FMC articulada à HFC, sua história e seu papel no desenvolvimento da Física, como tópicos a serem explorados em sala de aula da Educação Básica; no segundo momento, construiremos módulos separados por tópicos da Relatividade 
Restrita, com textos de apoio para os alunos e professores, privilegiando a abordagem conceitual do conteúdo e um enfoque histórico e filosófico da ciência. Logo, pretendemos abordar tanto a compreensão de fundamentos e princípios físicos, como a transformação e/ou fortalecimento de uma visão de ciência mais contemporânea e a articulação e desenvolvimento de habilidades de argumentação na acepção de Toulmin. As abordagens, análises e discussões serão elaboradas à luz do referencial teórico de Toulmin e Sacristán e, na medida que for necessário, será adotado alguns referenciais de análise, por exemplo, de Análise de Conteúdo.

\section{Resultados Esperados}

A investigação aqui apresentada, que se encontra na fase de aprofundamento teórico e de revisão da literatura, pretende, como já dito, compreender a percepção do aluno, enquanto sujeito da escolarização (particularmente da enculturação científica), sobre o ensino e aprendizagem de Física, em especial de FMC com foco na Relatividade; ouvir e interagir com seus professores, enquanto docentes atuantes, visando colaborar e construir uma sinergia entre universidade/pesquisadora-escola-professor-aluno. Entendemos que o uso da argumentação na acepção de Toulmin pode auxiliar a colocar em prática processos argumentativos e gerar melhorias na intenção de construir cidadãos críticos, participativos na sociedade, capazes de perceber o mundo contemporâneo como definido por uma singularidade irredutível e coletiva como princípio de transformação e capazes de assumir o risco da indignação, como propõe Negri (2015).

\section{The use of argumentation in Stephen Toulmin's sense articulated with the student-centered historical-epistemological approach: a possible way to build learning in relativity}

\section{Abstract}

We present a proposal for investigation and interventions in the thematic field of History, Philosophy and Sociology of Science articulated to the topic of Modern and Contemporary Physics (MCP) aiming to reach students from the Elementary School and their active teachers, which will be developed during the $\mathrm{PhD}$ research from a Postgraduate Program in Physics Teaching. There are two main objectives of our proposition with this study: to contribute to a scientific education that uses and integrates aspects of the History and Philosophy of Science (HPC) in the teaching- 
-learning process of concepts and principles of Relativity, seeking to question naive views about the nature of science; and build a synergy between University and school, focusing on listening and understanding the student's identity as a subject of schooling, discussion, dissemination and the uses of scientific argumentation, in the sense of Stephen Toulmin (1922-2009).

Keywords: History and Philosophy of Science; Modern and Contemporary Physics; Relativity; Scientific Argumentation.

\section{Notas}

1 TRR- Teoria da Relatividade Restrita.

\section{Referências}

ARTHURY, Luiz Henrique Martins. A natureza da ciência no ensino de física: entre recortes e sugestões. Revista do Professor de Física, v. 4, n. 2, p. 1-17, 2020.

AQUINO, G. T. M. "História da Ciência no Ensino Médio: caminhos para uma interdisciplinaridade possível”. Khronos, Revista de História da Ciência, n. 4, p. 14-31. 2017.

BELTRAN, Maria Helena Roxo; RODRIGUES, Sabrina Páscoli; ORTIZ, Carlos Eduardo. História da Ciência em Sala de aula-Propostas para o ensino das Teorias da Evolução. História da Ciência e Ensino: construindo interfaces, v. 4, p. 49-61, 2011.

BOGDAN, Robert C.; BIKLEN, Sari K. Investigação qualitativa em educação. Porto: Porto Editora, 1994.

BOTTURA JÚNIOR, Wimer. A gênese do adoecimento decorrente das agressões silenciosas. Psicoimunologia. In: ANGERAMI CAMON, V.A. (Org.). Psicossomática e suas interfaces: 0 processo silencioso do adoecimento. São Paulo: Cengage Learning, 2012. p. 389-396.

BRASIL. Base Nacional Comum Curricular, 2018. Disponível em: <http://www.planalto.gov.br/ ccivil_03/leis/19394.htm>. Acesso em: 12. out. 2020.

BRASIL. Lei nº 9.394, de 20 de dezembro de 1996. Estabelece as Diretrizes e Bases da Educação Nacional. Diário Oficial [da República Federativa do Brasil], Brasília, DF, v. 134, n. 248, 1996.

BRASIL. Orientações Educacionais Complementares aos Parâmetros Curriculares Nacionais PCN+ - Ensino Médio - Ciências da Natureza, Matemática e suas Tecnologias. Brasília: Ministério da Educação, 2002.

BRASIL. Parâmetros Curriculares Nacionais: Ciências da Natureza, Matemática e suas Tecnologias. Brasília: Ministério da Educação, 1999.

BRASIL. Conselho Nacional da Educação/Conselho Pleno. Resolução n. 4, de 17 de Dezembro de 2018. Institui a Base Nacional Comum Curricular na Etapa do Ensino Médio (BNCC-EM), como etapa final da Educação Básica, nos termos do artigo 35 da LDB, completando o conjunto constituído pela BNCC da Educação Infantil e do Ensino Fundamental, com base na Resolução CNE/ CP no 2/2017, fundamentada no Parecer CNE/CP nº 15/2017. Disponível em: <http://portal.mec. 
gov.br/index.php?option=com_docman\&view=download\&alias=104101-rcp004-18\&Itemid=30192>. Acesso em 05/10/2020.

CAVALCANTE, Marisa Almeida; TAVOLARO, Cristiane Rodrigues Caetano. Uma oficina de física moderna que vise a sua inserção no ensino médio. Caderno Brasileiro de Ensino de Física, v. 21, p. 372-389, 2004.

COSTA, Maria da Conceição dos Santos; FARIAS, Maria Celeste Gomes de; SOUZA, Michele Borges de. A base nacional comum curricular (BNCC) e a formação de professores no brasil: retrocessos, precarização do trabalho e desintelectualização docente Movimento. Revista de Educação, n. 10, p. 91-120, jan./jun. 2019.

CUESTA, Yeison Javier; MOSQUERA, Carlos Javier. Algunas Reflexiones en torno a las Implicaciones de la NdC en Educación en Ciencias: el caso de la Enseñanza de la Mecánica Cuántica. TED: Tecné, Episteme y Didaxis. Extraordinario, p. 921-927, 2017.

DAMASIO, Felipe; PEDUZZI, Luiz Orlando Q. História e filosofia da ciência na educação científica: para quê? Ensaio Pesquisa em Educação em Ciências, v. 19, 2017.

EL-HANI Charbel Niño; TAVARES, Eraldo José Madureira; ROCHA, Pedro Luís Bernardo. Concepções epistemológicas de estudantes de biologia e sua transformação por uma proposta explícita de ensino sobre história e filosofia das ciencias. Revista Investigações em Ensino de Ciências, v. 9, n.3, 2004.

ERTHAL, João Paulo Casaro; LINHARES, Marilia Paixão. História da ciência em sala de aula: o que tem aparecido em nossas revistas? Simpósio Nacional de Pesquisa em Educação e Ciências, 2009. Disponível: http://www.fep.if.usp.br/ profis/arquivos/viienpec/VII\%20ENPEC\%20 -\%202009/www.foco.fae.ufmg.br/cd/pdfs/966.pdf Acesso em 25/11/2020

FRANGELLA, Rita de Cássia Prazeres; DIAS, Rosanne Evangelista. Os sentidos de docência na BNCC: efeitos para o currículo da educação básica e da formação/atuação de professores Revista: Educação Unisinos, v. 22, n. 1, p. 7-15, 2018. DOI: 10.4013/edu.2018.221.01

FORATO, Thaís Cyrino Mello; PIETROCOLA, Maurício; MARTINS, Roberto Andrade. Historiografia e Natureza da ciência na Sala de Aula. Caderno Brasileiro de Ensino de Física, v. 28, n. 1, p. 27-59, 2011.

GARCIA, Nilson Marcos Dias; LOCH, Juliana. Física moderna e contemporânea na sala de aula do ensino médio VII ENPEC, nov 2009. Disponível em http://fep.if.usp.br/ profis/arquivos/viienpec/VII\%20ENPEC\%20-\%202009/www.foco.fae.ufmg.br/cd/pdfs/1335.pdf Acesso em 26/12/2020

GUIMARÃES, Lucas Peres; CASTRO, Denise Leal de. Visão dos professores de ciências da rede municipal de barra mansa, diante dos desafios da base nacional comum curricular (BNCC) Horizontes. Revista de Educação, v. 8, n. 15, p. 6-19, 2020.

GUIMARÃES, Ricardo Rangel; MASSONI, Neusa Teresinha. Argumentação e pensamento crítico na educação científica: análise de estudos de casos e problematizações conceituais: Revista Brasileira de Ensino de Ciência e Tecnologia, v. 13, n. 2, p. 320-344, mai./ago. 2020.

GURGEL, Ivã; PIETROCOLA, Maurício. Uma discussão epistemológica sobre a imaginação científica: a construção do conhecimento através da visão de Albert Einstein, Revista Brasileira de Ensino Física, v. 33, n. 1, 2011.

HÖTTECKE, Dietmar; SILVA, Cibelle Celestino. Why implementing history and philosophy in school science education is a challenge: an analysis of obstacles. Science \& Education, v. 20, n. 3-4, p. 293-316, 2011. 
JUNGES, Alexandre Luis; MASSONI, Neusa Teresinha. O Consenso Científico sobre Aquecimento Global Antropogênico: Considerações Históricas e Epistemológicas e Reflexões para o Ensino dessa Temática. Revista Brasileira de Pesquisa em Educação em Ciências, v. 18, n. 2, p.455-491, 2018.

JANERINE Ana Luiza de; QUADROS, Aline de Souza. A formação de professores: analisando uma experiência formativa. Revista Insignare Sciencia, v. 1, n. 1, 2018.

LIMA, Gilson. Redescoberta da mente na educação: a expansão do aprender e a conquistado conhecimento complexo. Educação e Sociedade, v. 30, n. 106, p. 151-174, jan./abr. 2009. Disponível em http://www.cedes.unicamp.br Acesso em: 10/10/2020

MASSONI, Neusa Teresinha; MOREIRA, Marco Antonio. Uma análise cruzada de três estudos de caso com professores de Física: a influência de concepções sobre a natureza da ciência nas práticas didáticas. Ciência \& Educação, v. 20, n. 3, p. 595-616, 2014.

MASSONI, Neusa Teresinha. A Epistemologia contemporânea e suas contribuições em diferentes níveis de Ensino de Física: a questão da mudança epistemológica. 2010. Tese (Doutorado em Ensino de Física) - Programa de Pós-Graduação em Ensino de Física, Universidade Federal do Rio Grande do Sul, Porto Alegre, 2010, 412f.

MASSONI, Neusa Teresinha. Epistemologias do Século XX. Textos de Apoio ao Professor de Física. v. 16 n. 3, UFRGS, 2005.

MARTINS, Roberto Andrade. A maçã de Newton: História, Lendas e Tolices. In: SILVA, C. C. Estudos de história e filosofia das ciências: subsídios para aplicação no ensino. São Paulo: Editora Livraria da Física, 2006.

MAQUINÉ, Gilmara Oliveira; AZEVEDO, Rosa Oliveira Marins. Competências na formação de professores: da LDB à BNCC. Revista Relações Sociais, v. 1, n. 1, 2018.

MATTHEWS, Michael R. História, filosofia e ensino de ciências: a tendência atual de reaproximação. Caderno Catarinense de Ensino de Física, v. 12, n. 3, p. 164-214, 1995.

MATTHEWS, Michael R. Science Teaching - The Role of History and Philosophy of Science. New York: Routledge, 1994.

MONTEIRO, Midiã. M.; MARTINS, André Ferrer P. História da ciência na sala de aula: Uma sequência didática sobre o conceito de inércia. Revista Brasileira de Ensino de Física, v. 37, n. 4. p. 4501-1-4501-9. 2015.

MOREIRA, Marco Antonio; MASSONI, Neusa Teresinha; OSTERMANN, Fernanda. História e epistemologia da física na licenciatura em física: uma disciplina que busca mudar concepções dos alunos sobre a natureza da ciência. Revista Brasileira de Ensino de Física, v. 29, n. 1, p. 127-134, 2007.

MOREIRA, Marco Antonio; MASSONI, Neusa Teresinha. Epistemologias do Século XX. São Paulo: Editora Pedagógica e Universitária, 2011.

MORTIMER, Eduardo Fleury; SEPULVEDA, Claudia Alencar Serra; EL-HANI, Charbel Nino. Construção de um perfil conceitual de adaptação: implicações metodológicas para o programa de pesquisa sobre perfis conceituais e o ensino de evolução. Investigações em Ensino de Ciências, v. 18, p. 439-479, 2013. Disponível em: https:/www.if.ufrgs.br/cref/ojs/index.php/ienci/ article/view/140 
NASCIMENTO, Silvania Sousa do., VIEIRA, Rodrigo Drumond. Contribuições e limites do padrão de argumento de Toulmin aplicado em situações argumentativas de sala de aula de ciências. Revista Brasileira de Pesquisa em Educação em Ciências, v. 8, n. 2, p. 1-20, 2008.

NEGRI, Antonio. Biocapitalismo: entre Spinoza e a constituição política do presente. $1^{\underline{a}}$ ed. São Paulo: Iluminuras, 2015..

OLIVEIRA, Rilavia Almeida de; MARTINS, André Ferrer Pinto; SILVA, Ana Paula Bispo. Temas de Natureza da Ciência à partir de episódios históricos: os debates sobre natureza da luz na primeira metade do século XIX. Caderno Brasileiro de Ensino de Física, v. 37, n. 1, p. 197-218, 2020.

PEDUZZI, Luiz Orlando Q. Sobre a utilização didática da história da ciência. In: PIETROCOLA, M. (Org.) Ensino de Física - conteúdo, metodologia e epistemologia numa concepção integradora. Florianópolis: Editora UFSC, 2001. p. 236-250.

PEREIRA, Marcus Vinicius ; BARROS, Susana de Souza. Análise da produção de vídeos por estudantes como uma estratégia alternativa de laboratório de física no Ensino Médio. Revista Brasileira de Ensino de Física, v. 32, n. 4, 2010

RAICIK, Anabel Cardoso.; PEDUZZI, Luiz Orlando Q. Um resgate histórico e filosófico dos estudos de Stephen Gray. Revista Brasileira de Pesquisa em Educação em Ciências, v. 16, n. 1, 2016.

RAICIK, Anabel Cardoso. Nos embalos da HFC: discussões sobre a experimentação e aspectos relativos à NdC em UEPS. Experiências em Ensino de Ciências, v. 15, n. 2, 2020.

ROCHA, Diego Marceli; RICARDO, Elio Carlos. As crenças de autoeficácia e o ensino de Física Moderna e Contemporânea. Caderno Brasileiro de Ensino de Física, v. 33, n. 1, p. 223-252, 2016. DOI: http://dx.doi.org/10.5007/2175-7941.2016v33n1p223

SACRISTÁN, José Gimeno. O aluno como Invenção. Porto Alegre: Artmed, 2005.

SASSERON, Lúcia Helena.; MACHADO, Vitor Fabrício. Alfabetização Científica na Prática: inovando a forma de ensinar Física. 1ํㅡㄹ ed, São Paulo: Editora Livraria da Física, 2017.

SEPULVEDA, Claudia Alencar Serra; MORTIMER, Eduardo Fleury.; EL-HANI, Charbel Niño. Construção de um perfil conceitual de adaptação: implicações metodológicas para o programa de pesquisa sobre perfis conceituais e o ensino de evolução. Investigações em Ensino de Ciências, v. 18 , p. $439-479,2013$.

SILVA, João Ricardo Neves da; ARENGHI Luis Eduardo Birello; LINO, Alex. Por que inserir física moderna e contemporânea no ensino médio? Uma revisão das justificativas dos trabalhos acadêmicos. Revista Brasileira de Ensino de Ciência e Tecnologia, v. 6, n. 1, p. 69-83, 2013.

SOLBES, Jordi; SINARCAS, Vicent. Utilizando la historia de la ciencia en la enseñanza de los conceptos claves de la física cuántica. Didáctica de las Ciencias Experimentales y Sociales, v. 23, n. 1, p.123-151, 2009.

STAKE, Robert. Investigación con estudio de casos. Ediciones Morata, S. L., Madrid, 1999.

STAKE, Robert. Pesquisa Qualitativa: estudando como as coisas funcionam. Tradução: Karla Reis; revisão técnica: Nilda Jacks. Porto Alegre: Penso, 2011.

TOULMIN, Stephen E. Os usos do Argumento. São Paulo: Martins Fontes, 2006.

TOULMIN, Stephen E. The Uses of Argument, Updated Edition, Cambridge University press, 2003. 